\title{
Mallorca ante la Guerra de la Convención Francesa. Defensas, movilización popular y levantamiento de milicia ${ }^{1}$
}

\author{
María del Carmen Corona MarzoL \\ Universidad Jaume I de Castellón \\ corona@uji.es
}

Fecha de recepción: 01/02/2012

Fecha de aceptación: 01/09/2012

\section{RESUMEN}

La Guerra de la Convención (1793-1796), enfrentó a la monarquía española con la Francia revolucionaria. Este episodio bélico que alteró la política internacional del momento, y situó a la isla de Mallorca en posición de alerta, como punto estratégico del Mediterráneo Occidental. La isla se movilizó con una considerable aportación de hombres, que se redujeron en un importante número de compañías de milicias urbanas, mientras las tropas reales socorrían la Península y Cataluña.

Palabras clave: Guerra de la Convención, Mallorca, Milicias urbanas, Movilización popular, Defensas, Fortificaciones.

\section{Mallorca Faces the War of Convention. Defences, Popular Mobilization and Militia Recruitment}

\begin{abstract}
The War of the Convention (1793 to 1796) pitted Revolutionary France against the Spanish monarchy during the French Revolutionary Wars. This military episode altered international policy of that period and placed Majorca on alert as strategic site in the western Mediterranean. The island mobilised considerable number of men organised in a large number of urban militia while royal troops came to the aid of the Iberian Peninsula and Catalonia.
\end{abstract}

Key words: War of the Convention, Majorca, Urban Militia, Popular Mobilization, Defences, Fortifications.

\footnotetext{
1 A mi hijo Rafa, en recuerdo de sus vivencias en Palma y Mallorca. Este artículo ha sido realizado dentro del proyecto: Politica económica, circulación internacional de ideas económicas y esfera pública en España, 1680-1840. Ref. HAR2011-29036-C02-01. Investigador principal: Guillermo Pérez Sarrión, Universidad de Zaragoza. Financiado por el Ministerio de Economía y Competitividad. 
Para que sostengan al soberano en posesión de este Reino... dilatando la vigorosa defensa del País y dando lugar al socorro del continente... que la robustez, espíritu y viva ansia que manifiestan estos naturales de sacrificarse en obsequio de su Príncipe... promete rizo al que lo insulte e inconquistable al Reino.

(Palma, 5 de octubre de 1793)²

\section{Mallorca ante la Guerra de la Convención}

La circular del Supremo Consejo de Castilla del 6 de Febrero de 1793, urgía a los Capitanes Generales, Comandantes y Justicias de los diversos reinos y territorios de la Monarquía a una movilización general. El mismo día de la publicación de la Circular en la Gaceta de Madrid, comenzaron a aparecer listas de voluntarios.

La Convención Nacional de París había declarado la Guerra a España el 7 de marzo de 1793. La justificación diplomática se basaba en la existencia de una serie de agravios y ultrajes a la soberanía de la Nación Francesa, acumulados desde el 14 de julio de 1789. Tal declaración dio paso a un Decreto de la Nación. La contestación española no se hizo esperar. El 23 de marzo de 1793, 4 días después se hizo la publicación de la Guerra en la Corte, y la Declaración de Guerra desde Madrid. El rey Carlos IV deseaba vengar la muerte de su pariente y dar satisfacción a los vasallos que querían enfrentar la amenaza de la revolución.

En consecuencia la isla de Mallorca recibió la Circular General, así como el deseo real de que la isla se preparase para la previsible guerra contra los franceses. La adhesión y el ofrecimiento de colaboración del reino fue inmediata, y semejante en disponibilidad y euforia a otros lugares y ciudades de España. La nobleza, el clero, los ayuntamientos, particulares y el pueblo en general se manifestaron con prontitud ante la llamada real y la posible invasión anunciada. En poco tiempo se habían alistado 23.677 hombres, reclutados entre las 38 poblaciones de los 15 cuartones mallorquines. Una cifra desmesurada si se tiene en cuenta la población global masculina existente.

La nobleza regnícola, los caballeros insulares, respondieron casi en su totalidad, como lo habían hecho en ocasiones anteriores ante la petición de auxilio del monarca. En esta ocasión se personaron ante el comandante general y luego ante el teniente del rey de la plaza de Palma, el marqués de Campofranco, y una vez reunidos eligieron a dos de ellos, en calidad de comisionados, para exponer sus deseos de colaboración y tratar su posición ante el comandante y capitán general de las islas, Bernardo de Tortosa. Ante él manifestaron su decisión de prestar los servicios necesarios en "defensa de la Patria, sus personas y haciendas", afirmando que lo harían todo a sus costas. Así mostraban una vez más su fidelidad a la Corona y el apoyo en los momentos de urgencia.

Además de la nobleza, y como fue común en el territorio peninsular, el clero se distinguió también por sus ardientes proclamas y la acción de concienciar a los creyentes

2 Archivo General de Simancas (en adelante, AGS.) Guerra Moderna, leg. 6447. Carta del Comandante General, Marqués de Castelldosrius al Marqués de Campofranco. 
en la defensa de la fe, la religión y la moral frente al deísmo revolucionario y el temido destronamiento de la institución eclesiástica. Mallorca vivió el mismo sentimiento de apoyo a la religión y a sus ministros. Los obispos exhortaron a los respectivos párrocos y religiosos a que se esforzaran en sus ministerios, predicaran la defensa del legitimismo real y de la religión, proclamando las obligaciones del católico leal.

\section{Plan defensivo y militar de Mallorca}

Dadas las condiciones militares de las diferentes plazas y lugares de las islas se procedió a establecer un plan defensivo y militar de Mallorca ${ }^{3}$. La correspondencia entre la Capitanía General y la Secretaria de Estado de Guerra pone de manifiesto las dificultades de todo tipo existentes, pero sobre todo las referidas al estado del sistema defensivo y los recursos armamentísticos disponibles. El proyecto de las dos altas instancias de Palma, Capitanía General y Tenencia del Rey, desaprobaba la utilización del pueblo espontáneo y el alistamiento generalizado por razones tanto militares como de orden público.

El núcleo del plan ideado consistía en movilizar las antiguas milicias existentes en las diversas ciudades, poblaciones y lugares. Estas milicias, denominadas en la época de Carlos III como urbanas, debían establecerse preferentemente tanto en la capital como en los otros núcleos relevantes de la Marina, pero también en los espacios interiores de mayor población o importantes por sus actividades económicas, como la agricultura, la industria y el comercio. La integraban los vecinos correspondientes de cada localidad cuyas familias, propiedades y oficios constituían una razón tan sólida como efectiva, cara a la movilización efectiva del territorio ${ }^{4}$.

A esta propuesta se unió la corporación municipal de Palma. También ella comunicó con rapidez la necesidad de reforzar las defensas de la isla, y contar con el restablecimiento de la ayuda vecinal, tal y como era de ley consuetudinaria, que los habitantes cualificados colaborasen al servicio del rey y de su territorio. La formula histórica eran las milicias cívicas, a las que se debían poner en pie de guerra lo antes posible, ratificando este argumento en los siguientes términos:"deviéndose contar con ellas como un Pueblo armado cuando se tocan los somatenes".

El conocimiento de la realidad defensiva y militar de la isla preocupaba hondamente a los responsables institucionales y militares. Por ello, mientras se procedía a organizar el levantamiento de las milicias, se llevó a cabo la realización de una pesquisa. Esta inspección general era vital para conocer el estado actual de Mallorca. No solo era importante constatar el estado del terreno, con las modalidades de la constitución geográfica de las costas y del interior, sino lo relativo a la situación de las

3 Como referencia anterior véase: CASAnOva, U.: «El sistema defensivo de Mallorca en el siglo XVII» en Estudis, 12 (1985-1986), pp. 217-232.

4 Corona Marzol, C.: «Las milicias urbanas del siglo XVIII: Compañías de reserva y paisanaje» en Ruiz Ibañez, J.J (Coord.): Las milicias del rey de España. Sociedad, política e identidad en las Monarquías Ibéricas, Madrid, 2009, pp. 437-459.

5 AGS. Guerra Moderna, leg. 6447. 
defensas, deterioro de las fortificaciones, posibles efectivos existentes y dotaciones de la artillería ${ }^{6}$.

El marqués de Campofranco, militar de impecable trayectoria y eficientes habilidades técnicas, recibió la real orden de encabezar una selecta Comisión encargada de inspeccionar en profundidad lo indicado e informar al Duque de Alcudia de los resultados. Como en otras ocasiones, se esperaban incursiones o la invasión de la isla, ya fuese por los franceses, sus aliados coyunturales o el corso siempre presto a aprovechar cualquier ocasión favorable para obtener ventaja. Tres personas hábiles y competentes le acompañaron en la misión: un ingeniero, Manuel Pueyo, teniente coronel de Ingenieros; un alférez del Cuerpo de Artilleros, José Gagandos; y un marino, el teniente de fragata Onofre Gomila. Su deber era sondear toda la costa, constatar sus informes en relaciones minuciosas con las observaciones necesarias para la salvaguardia de la patria ${ }^{7}$.

Por las informaciones enviadas tenemos conocimiento de la complejidad de la situación y la escasez de medios artilleros y pertrechos militares. El 5 de octubre de 1793 ya se disponían de los datos básicos para poder tener una composición de lugar, más o menos acertada. Con tres relaciones en forma de cuadros sintéticos, a la usanza del sistema militar borbónico, recogieron todo lo esencial para diseñar un plan defensivo y militar. El Estado General de los puertos, bahías, ensenadas y calas, daba noticias de las 85 posibles zonas de desembarco en la isla, excluyendo las calas pequeñas y medianas, en el resto podían fondear buques de todos portes, y en algunas ensenadas se podían abrigar grandes expediciones.

El estado general de los castillos, baterías y torres existentes en toda la circunferencia de la isla fue elaborada entre el 24 de agosto y el 2 de octubre de 1793. En el se especificaba la existencia de 8 castillos, 27 torres, 3 de ellas sin artillar, y 13 torres vigías, entre otras construcciones ${ }^{8}$.

El informe constataba que algunos de los fuertes se encontraban en franca decadencia, con corto diámetro y poca resistencia para aumentar el número de los cañones. Respecto a los cuarteles existentes la mayoría estaban adecuados para la caballería, aunque estaban ocupados por un exceso de hombres, en proporción a los caballos existentes. La mayor parte de los hombres se alojaban en casas particulares a cuenta de las villas, el único era el cuartel de Inca, situado fuera de la costa. En Alcudia tres de los cuatro cuarteles militares estaban en condiciones adecuadas. La artillería era en general escasa, y no estaba en las mejores condiciones ${ }^{9}$.

El último de estos informes recogía las divisiones territoriales de los distritos antiguos de Mallorca. Las villas y pueblos de la isla comprendían 15 distritos, y en total

6 Sobre las fortificaciones de Mallorca: CÁmARA, A.: Fortificación y ciudad en los reinos de Felipe II. Madrid. 1998. DeYÀ, M.: «La geoestratègia mediterrània en el segle XVI. El seu impacte en la creaciò del sistema defensiu balear» en VV.AA: I Centenari de l'enderrcoament de les murades de Palma, 1902-2002. Palma. 2004. Tous Melíé, J.: «Las murallas de Palma durante la Edad Moderna» en VV.AA: I Centenari de l' enderrcoament de les murades de Palma, 1902-2002. Palma. 2004.

7 AGS. Guerra Moderna, leg. 6447.

8 Véase Cuadro I.

9 Un antecedente claro en el estudio de: Casanova, U.: «Los alojamientos de soldados en el reino de Mallorca a lo largo del siglo XVII» Marurqa, 22, (1989), pp. 733-744. 
podían calcularse una población útil para el servicio militar de 1181 hombres, entre todos ellos ${ }^{10}$.

Con todos estos datos se procedió a la organización y conformación de un ejercito ciudadano en armas, constituido sobre las bases de las milicias urbanas.

\section{La participación de la nobleza}

Como conocemos, los caballeros de la isla de Mallorca se ofrecieron a colaborar inmediatamente con la Comandancia y Capitanía General ${ }^{11}$. Si en un principio se personaron algunos a ofrecer sus servicios, la adhesión posterior fue mucho mayor. Se comprometieron a constituir las milicias y acaudillarlas, cada uno en su respectivo territorio. El reclutamiento se realizaría en las villas y ciudades de los denominados cuartones históricos, en concreto en 38. Los gastos generales correrían a sus expensas, por lo que se solicitó una serie de prebendas al monarca, dentro de las usuales peticiones requeridas en estas circunstancias ${ }^{12}$.

Desde la Comandancia General se trasladaron los requerimientos de la nobleza, que incluían fundamentalmente el fuero militar y los reales despachos correspondientes. Las peticiones eran sensatas y adecuadas a las circunstancias bélicas del armamento general, y había sido la practica habitual en las milicias urbanas peninsulares ante situaciones de emergencia, sin embargo en las islas Baleares las concesiones anteriores habían sido distintas. La cuestión planteó una diferenciación de excelencia dentro del contexto insular. Las milicias mas ejercitadas de las Baleares habían sido las de Ibiza y Formentera a lo largo de los siglos de la modernidad, y en concreto, en el Siglo de las Luces las había puesto en pie la monarquía en diversas ocasiones de riesgo general, ya fuese por las posibles agresiones de las potencias europeas enemigas circunstanciales de la Corona o por los ataques habituales de la piratería o el corsarismo ${ }^{13}$. El 4 de agosto de 1754 se les concedieron los despachos y el fuero militar en el ámbito criminal ${ }^{14}$.

En las presentes circunstancias de guerra contra la Francia revolucionaria, la nobleza solicitó un tratamiento especial, que sentara una clara diferenciación con sus homologas insulares. Si antes los despachos se concedieron desde la Capitanía General mallorquina, ahora debían ser ratificados y firmados desde las instancias reales. El fuero militar debía concederse a la totalidad de la oficialidad, sargentos incluidos, cuya demanda se trasladó a las dependencias de la Secretaria de Guerra con la si-

10 Véase Cuadro II.

11 Sobre la Capitanía General: CAIRIMi CALAfat, T.: «El establecimiento de las capitanías generales en el siglo XVIII: el caso del Reino de Mallorca y sus primeros mandos: el caballero de Asfeld y el marqués de Lede» en La guerra de la sucesión en España y América: actas X jornadas nacionales de Historia Militar. Madrid. 2001. Andujar Castillo, F.: "Capitanes generales y capitanías generales en el siglo XVIII", Revista de Historia Moderna. Anales de la Universidad de Alicante, 22 (2004), pp.7-78.

12 Véase Cuadro III.

13 López NAdAL, G.: El corsarisme mallorquí a la Mediterránea Occidental, 1652-1698. Un comerç forçat, Palma. 1986. BiBiloni, A.: «Reforma económica i "legalització” del contraban a Mallorca» Randa, 26, Barcelona, (1990), pp. 85-102.

14 AGS. Guerra Moderna, leg. 6447. 
guiente argumentación: "Todos se habían comprometido a defender la Patria, a sostener en ella el decoro del Rey y los intereses y relaciones con el resto del Estado" 15. Mallorca era muy consciente de su posible papel de antemural defensivo frente las potencias aliadas de Francia o de las que colaboraban con Carlos IV, cuyos intereses desvelados en las correspondencias diplomáticas, no eran lo que aparentemente parecían, y cuyo debate en la corte había causado disputas y relevos en la Secretaria de Estado. El 17 de Junio de 1793 se concedió a la nobleza lo solicitado, "mientras dure la guerra".

Conocemos los miembros de la nobleza y títulos que asumieron la defensa de la isla ${ }^{16}$. La Relación de los Caballeros de esta ciudad que se proponen para capitanes de las Milicias urbanas, a fin de resguardar la isla en lo interior y su Marina ${ }^{17}$, nos informa de los linajes mas antiguos y acrisolados de Mallorca y otros lugares peninsulares. Sobresalen entre ellos, el marqués de Casteldosrius, marqués de Reguer, marqués de la Torre, conde de Formiguera, y el marqués de Vilafranca. Dos comendadores, Nicolás Armengol y Ramón Fortuny, completaban el conjunto entre una lista de ciudadanos meritorios hasta el numero de 29 individuos. El rey conoció la aportación mallorquina el 1 de abril de 1793.

Desde la Comandancia general se les patrocinaba por el "aprecio, celo y disposición" con que se habían comprometido a servir su encargo. La elección de la oficialidad fue objeto de los capitanes, siguiendo los criterios del marqués de Casteldosrius y las disposiciones específicas y generales de las milicias urbanas. Como era habitual en el siglo XVIII entre las cualidades requeridas para la oficialidad, todos eran sujetos de notorio y decente linaje, "vivero de sus haciendas" y ninguno ejercia oficio mecánico alguno, correspondiente todo ello con el carácter propio de un oficial. Los sargentos debían de ser hacendados de las poblaciones, individuos respetados en sus respectivos lugares y de "conocido espíritu" 18 . A los cabos se les exigía buena conducta y saber escribir, además de tener en cuenta prioritariamente los que hubiesen servido en el uso de las armas. No interesa aquí precisar el nombre y calidad de cada uno de estos oficiales y subalternos, pero desde la sociología militar ofrecen un buen repertorio de matices y cualidades de la sociedad mallorquina, y de las familias y apellidos del estamento ciudadano. Disponemos de los listados de cada uno de los grados con sus individuos y familiares. Siguiendo los criterios militares generales todos fueron elegidos por su nacimiento y aptitud ${ }^{19}$.

El duque de Alcudia, ya Secretario de Estado desde su ascenso en noviembre de 1792 tras la sustitución del conde de Aranda, mantuvo una correspondencia continuada con el marqués de Casteldosrius. Entre los papeles figura una relación de diferentes particulares que ofrecieron también mantener a su costa diferentes partidas

15 AGS. Guerra Moderna, leg. 6447.

16 A lo largo del siglo XVIII ya se habían establecido movilizaciones semejantes: FERNÁNDEZ DE Bethencourt, F.: «Alistamiento noble de Mallorca del año 1762» Boletín de la Real Academia de la Historia, 60 (1912), pp. 507-513. Ramis D’Aireflor, J.: «Alistamiento noble de Mallorca en 1762» en Noticias genealógicas heráldicas y bibliográficas de los individuos y familias contenidas en el mismo, Palma, 1911, pp. 416-418.

17 AGS. Guerra Moderna, leg. 6447.

18 AGS. Guerra Moderna, leg. 6447.

19 Andujar Castillo, F.: Los militares en la España del siglo XVIII. Un estudio social, Granada, 1991. 
de hombres a caballo para la defensa de la isla. Entre ellos sobresale el coronel marqués de Campofranco. Otros se comprometieron a contribuir en metálico. Es el caso del sargento de cazadores del Regimiento de Milicias Provinciales, Miquel Nadal, y de Pedro Net, antiguo y distinguido miembro también de las Provinciales. Este dato además de reforzar la actitud de muchos de los particulares que ayudaron con dinero a sufragar la Guerra de la Convención en otros territorios como Aragón, demuestra en el caso mallorquín la existencia y cooperación de los oficiales de las otras milicias existentes en el territorio, que en Mallorca tuvieron otros cometidos, como veremos más adelante ${ }^{20}$.

\section{La formación de las compañías y la instrucción militar}

La movilización de Mallorca y las listas confeccionadas desde la Comandancia General demostraron la existencia de 23.685 varones en su totalidad. La distribución por edades y las cifras resultantes de las tres clasificaciones utilizadas, siguiendo los criterios habituales de la administración borbónica, dan idea de la población real de la isla, aunque ponen de manifiesto la paralización general que supondría la recluta de todos estos hombres al separarlos de sus respectivos pueblos, familias y casas. El número de exceptuados alcanzó la cifra de 2.043 hombres. Sin embargo desde el prisma de las autoridades militares, todos ellos junto a los individuos comprendidos en el Fuero de Marina, formarían un "cuerpo de reserva", que según las circunstancias pudiera servir a semejanza de un ejercito popular.

El reclutamiento se materializó sobre la base de 23.677 varones útiles, extraídos entre los 15 distritos insulares mencionados y correspondientes a las 38 villas y poblaciones representativas por su población o situación geográfica. De ellas las que más hombres aportaron fueron Pollensa con 400 individuos, seguida por Inca y Manacor, con 200 y 170 respectivamente. La menor partida la ofrecieron otras 12 villas con 5 hombres cada una. Pueden verse los datos concretos en los cuadros aportados al final del texto.

Como era habitual, los militarizados se subdividieron en tres clases o categorías por edades. La base substancial la constituyeron los comprendidos entre 16 y 50 años, cuya suma resultante ofreció la cifra de 19.411 hombres. Les seguían los situados entre 50 y 60 años, su aportación dio como resultado a 2.532 aptos para el servicio. Todos los restantes, entre 14 y 16 años, formaban la tercera clase, cuyo número completó la cifra tota ${ }^{21}$.

Mientras se efectuaba el recuento de los posibles efectivos militares, se hizo el inventario del armamento. Lo primero que llamó la atención fue la escasez de armas, piedras de chispa y pólvora, existentes en las poblaciones. La mayor parte de ellas, unas 3.558 piezas, estaban en manos de los particulares, y lo constituían fusiles, escopetas y pistolas. En el total de los ayuntamientos solo existían 707 armas, la mayor

20 AGS. Guerra Moderna, leg. 6447.

21 Véase Cuadro IV. 
parte escopetas. La mayoría de las villas no tenían municiones y carecían absolutamente de piedra de munición.

Ante estos datos y la necesidad de proceder lo más rápidamente posible a poner la isla en condiciones de defensa, el marqués de Casteldosrius elaboró una Instrucción para la formación y régimen militar de Mallorca.

Este documento en formato de Reglamento, aclara los puntos fundamentales sobre la articulación defensiva concebida desde la Comandancia General. El texto preciso y riguroso especifica primeramente la formación de las milicias urbanas en compañías, con las dotaciones correspondientes de hombres y oficialidad. Se indicaba pormenorizadamente la clase y calidad de los miembros de la oficialidad, y las atribuciones que en su elección gozaban los caballeros, como capitanes de las milicias ${ }^{22}$.

En este punto Casteldosrius proponía la formación de 29 compañías de 228 hombres cada una, al frente de las cuales se colocaba la oficialidad, incluidos todos los miembros recomendables, que venían a ser 6 sargentos, 8 cabos primeros, 12 cabos segundos y un tambor. Todo debía ejecutarse según el orden y método conveniente. Las subdivisiones se adaptarían a las circunstancias del terreno.

La diferencia existente entre el volumen de alistados voluntarios al declararse la guerra y el recuento del marqués de Campofranco, con las cifras finales de las compañías de milicias, tiene su explicación fundamental en el escaso y defectuoso armamento existente en la isla. Los informes remitidos al conde de Campo de Alange especifican con precisión esta difícil situación. Casteldosrius escribía en estos términos: "Exceden extraordinariamente el número de hombres al de las armas, solo hay en la armería poco más de $7.000, \ldots$ reduje a 6.583 las plazas con los tambores incluidos, dándoles 100 fusiles por compañía, para dejar a los eventos los restantes de la ciudad". En consecuencia solicitó a la secretaria de guerra la cifra de 16.000 fusiles con sus piezas y chispas. En el pensamiento de este Comandante y Capitán General de Mallorca, estaba la posibilidad de tener que levantar al total contingente de movilizados por la Patria ante la posible invasión de las islas Baleares. Debía por tanto preverse el armamento de todo el pueblo movilizado. Se le contestó el 24 de febrero de1794 desde Aranjuez, con la concesión de las piezas de chispa, pero "supeditándose los fusiles ínterin no haya mas urgencia". En consecuencia los contingentes armados se redujeron a 6.583 individuos y las compañías compuestas por 200 individuos únicamente.

La Instrucción atendía especialmente a la preparación militar de los civiles, insistiendo en la necesidad de efectuar maniobras continuamente, atendiendo las líneas de formación, manejo de armamento y precisión del tiro. La intención de Casteldosrius estaba en conseguir soldados de los milicianos. Son significativas las partes de la Instrucción dedicadas a la enseñanza de las tropas, con maniobras propias de un ejercito del Siglo de las Luces: estaría reducida a dos formaciones, con indicación de los giros a derecha e izquierda, subdivisiones de mitades, cuartas y octavas partes, con indicaciones puntuales sobre la carga de las armas y el acierto en el manejo de hacer fuego. Las indicaciones sobre la formación militar de batalla no pueden ser más contundentes:

22 AGS. Guerra Moderna, leg. 6447. 


\begin{abstract}
“El capitán a la cabeza de la compañía. Uno de los tenientes a la izquierda de la segunda mitad, y ala izquierda de la primera el otro. A la retaguardia de uno y otro los dos subtenientes guardando el mismo orden en la colocación de los sargentos. Los cabos igualmente para proporcionar el buen manejo pasaran a la columna .Con este arreglo los oficiales deben estar en el lugar para sostener la unión y facilidad de cambiarla en la batalla".
\end{abstract}

La Relación de las propuestas de empleo recoge los apellidos más habituales y comunes a varias poblaciones insulares. Entre ellos recogemos los que nos parecen más representativos: Llado. Bonet, Font, Llobera, Mayol, Trias, Despuig; Fortuny, Montaner, Torrallo; Serra de Gayeta, Martorell, Cañellas, Pons... ${ }^{23}$ Todos ellos ocuparon puestos diversos en la oficialidad de sus respectivas poblaciones.

\title{
Los problemas de Palma y las dotaciones militares de Mallorca
}

Como en otras partes de la Península, el ayuntamiento de Palma se encargó de enumerar los inconvenientes y problemas que esta voluntaria participación a favor del Rey, la Religión y la Patria suponía para la mayor de las islas Baleares. Otros tantos memoriales como este se fueron acumulando entre los papeles destinados a la aprobación del duque de Alcudia, reiterando la resistencia de las municipalidades más importantes de España a los esfuerzos de todo tipo que el proceso implicaba.

Los datos comunicados por la ciudad de Palma son de enorme importancia para el historiador. En 1786 poblaban la isla unas 136.000 almas. Desde entonces la población se había diezmado por diferentes epidemias, de las cuales peligraba en el momento por una de peste, procedente de Mascara, en Orán y Argel, extendida en 1793 por varios puntos del Norte de África. A pesar de que el cabildo había dado orden de cerrar el tráfico portuario a todos los pueblos de la isla, a excepción de Palma, el peligro subsistía. Más de seis barcos guardacostas vigilaban la entrada de embarcaciones procedentes de esas zonas. Se había intentado duplicar las guardas de las torres marítimas y las rondas de atajadores velaban por las noches, patrullando con sus hombres las costas ${ }^{24}$.

Con este episodio se aprovechó desde Mallorca para llamar la atención sobre la posición geográfica y estratégica de la isla, víctima siempre del azote de las pestes, cuyas precauciones hasta la fecha habían sido escasas por la falta de hombres disponibles. En este punto la ciudad informaba de las dotaciones reales de la isla y los efectivos de todo tipo disponibles.

En el resguardo de la costa estaban empleados habitualmente 54 hombres en las torres como vigías, y solo 79 guardas custodiaban los parajes de mayor riesgo, distribuidos por el perfil de la línea marítima. Una porción de hombres de la Marinería se encargaban del control del comercio exterior, supervisando las entradas y salidas de los productos habituales de la importaciones y exportaciones de la isla, cuya necesaria presencia los hacia insustituibles

23 AGS. Guerra Moderna, leg. 6447.

24 AGS. Guerra Moderna, leg. 6447. 
Al ser Mallorca un territorio fundamentalmente agrícola, la monarquía extraía anualmente parte de su producción cerealística para el suministro del ejército real ${ }^{25}$. Habitualmente estos suministros se enviaban a Cataluña, con el fin de abastecer los regimientos de la frontera con Francia, tan castigada en el siglo pasado y amenazada e invadida en el curso de la actual contienda. En 1793 más de 60.000 quintales de paja se habían destinado al ejército del Rosellón, por asiento para el sostenimiento de la caballería, quedando solo 100 para el mantenimiento de los contingentes de la isla. Siguiendo estos abastecimientos durante la mayor parte de la época moderna se desprende la afirmación de que Baleares, y en concreto Mallorca, vinieron a constituirse en el Granero de Cataluña.

La urgencia de hacer frente a las propias necesidades, tanto de hombres como de suministros, hizo procedente el recordar al duque de Alcudia y al Rey las contribuciones del reino en las actuales circunstancias. Textualmente se comunicó "que aunque pudiesen contribuir proporcionalmente con menor numero de gentes, que las demás provincias de España", más de 7.000 mallorquines estaban empleados en el Ejército y en la Marina, cifra que consideraban escandalosa ${ }^{26}$. El reino aportaba dos regimientos de Milicias Provinciales, y un batallón completo de ellos tenía orden de trasladarse al Rosellón, con lo que se habían tenido que reemplazar sus faltas con gente externa, quedándose el segundo batallón únicamente con 370 hombres para la defensa de la isla ${ }^{27}$.

Del regimiento de Dragones del Rey, solo permanecerían en Mallorca dos escuadrones ya que había orden de salir para otros destinos peninsulares el resto de los hombres. A estas bajas se unían otras menores, como la salida de otros 70 soldados con destino al continente, permaneciendo únicamente la escasa tropa reglada para tiempos de paz. El problema militar se complicaba si se tenía en cuenta la custodia adicional de prisioneros franceses, que en el momento eran 600 individuos, cuya guarnición requería efectivos adicionales.

Las reflexiones de la corporación municipal de Palma se dirigieron a comparar su aportación militar con el resto de España. Esgrimieron que de los diez millones de habitantes existentes, las otras provincias debían contribuir al menos con 500.000 hombres, hecho que no se estaba produciendo, y en su lugar el esfuerzo de las Baleares las estaba dejando desarticuladas frente al posible enemigo.

La solución de Mallorca ante la difícil situación militar fue contar con sus propios habitantes para el resguardo y defensa de la isla.

25 Unos antecedentes claros en: JuAn VidaL, J: «El comercio de trigo entre Mallorca y África del norte en los siglos XVI y XVII» Mayurqa, 15 (1976), Palma, pp.73-92. CAsanova, U.: «El déficit alimenticio del reino de Mallorca a lo largo del siglo XVII y sus problemas de abastecimiento» Mayurqa, 21 (1985-1987), Palma, pp. 217-232.

26 Alomar, A.: El exèrcit mallorquí. De la fi de l'edat mitjana a la seva desaparició. Palma. 1998. CAsanova, U.: «Los alojamientos de soldados en el reino de Mallorca a lo largo del siglo XVII» en Marurqa, 22, (1989), pp. 733-744. WeYLER, F.: Historia orgánica de las fuerzas militares de Mallorca, desde su conquista en 1220 hasta nuestros días, Palma, 1862.

27 Corona Baratech, Carlos: «Las milicias provinciales del siglo XVIII como ejército peninsular de reserva» en Temas de Historia Militar, 1. Zaragoza. 1982, pp. 329-367. Corona Marzol, Carmen: «Valencia y las milicias provinciales borbónicas. Intentos de introducción y oposición institucional en el XVIII» Millars: Geografia-Historia, 11, (1986-1987), pp. 99-112. ConTreras GAY, J.: Las milicias provinciales en el siglo XVII. Estudio sobre los regimientos de Andalucía. Maracena, 1993. 


\section{Conclusiones}

Las milicias urbanas cumplieron el papel que les fue encomendado, como en otros periodos históricos en los que la Península y las islas Baleares fueron amenazadas. Antes por franceses, ingleses o holandeses, ahora por la Convención de la Francia revolucionaria.

Aunque su cometido seguía siendo ayudar en la defensa de los fuertes y las torres costeras, ocuparon las guarniciones para la vigilancia de los barcos procedentes de África, sirviendo como resguardo de la costa, ante la peste y el contrabando. Además, se les encomendó la vigilancia de los prisioneros franceses, acometiendo las funciones de la seguridad pública, para cuyo cometido fueron creados en otras ciudades y posesiones españolas. Atendieron el resguardo del traslado de la convoyes de víveres, y utensilios para el suministro de las tropas veteranas que permanecieron en la isla, y el acompañamiento de las de rentas, cuya misión no correspondía al ejército veterano.

Volvieron una vez más a ser el ejército de reserva, y en este caso, curiosamente existiendo regimientos de Milicias Provinciales, cuya finalidad histórica en su creación, era exactamente esa.

Mallorca fue el único territorio español de la antigua Corona de Aragón donde se establecieron Provinciales. Tanto en Cataluña como en Valencia y Aragón, la oposición institucional fue definitiva sin llegar a constituirse estas unidades llamadas a ocupar la defensa interior. Sin embargo, continuó siendo un puntal de abastecimiento militar para la Monarquía española tanto en efectivos humanos como en utensilios militares.

Conocemos cómo gran número de mallorquines formaron parte primero en los tercios de los Austrias, constituyendo una unidad específica, y cómo luego continuaron formando parte de los Regimientos de los Borbones adoptando su nombre propio.

Mallorca fue un territorio suministrador de hombres a lo largo de toda la Edad Moderna, cuyo destino fue normalmente el apoyo militar a Cataluña. En 1793, socorrieron al Rosellón y abastecieron al ejército real con cereales y frutos de la tierra como lo habían hecho con los últimos Austrias, perjudicando los propios intereses insulares.

Dejando aparte el periodo concreto de la Guerra de la Convención, enfrentamiento tan inútil como infructuoso pero alarmante, cabe preguntarse los motivos de la actitud de la isla mayor de las Pitiusas siempre tan predispuesta al socorro militar de la Corona española. Fuese como fuese, las circunstancias específicas de la política internacional y bélica con las otras naciones a través de los tiempos, siempre tuvieron en su punto de mira a las Baleares.

La explicación más esclarecedora radica en su posición estratégica en el Mediterráneo occidental, sin abandonar por ello las razones de lealtad a la Corona o la vinculación consuetudinaria con los acontecimientos de la Península y más concretamente con la Corona de Aragón a lo largo de los tiempos.

La movilización en 1793 de 23.685 hombres útiles, fue similar en entusiasmo y patriotismo respecto a los otros territorios, pero numéricamente impresionante para la población existente. Estos hombres, movilizados por la Patria, se mantuvieron en pie hasta los tratados de la Paz de Basilea en 1796. La propia correspondencia entre el 
Comandante General y del Teniente del rey con el duque de Alcudia, Manuel Godoy, así lo especifica. "Además de sostener al soberano en posesión de este Reyno...daban lugar al socorro del continente".

Cabe preguntarse, por último, otra cuestión de interés al analizar esta masiva participación de Mallorca. La noción que salta a la vista, tras el estudio de los documentos consultados, es la aplicación del concepto de Patria, tan utilizado en la correspondencia oficial con la monarquía, y en las cartas y oficios internos entre las instituciones de la isla.

Si analizamos la utilización del termino al referirse a la amenaza frente al enemigo exterior, la Patria adquiere el concepto de la legitimidad, de los vínculos jurídicos, políticos y afectivos, donde la pertenencia de los súbditos a la monarquía de España, adquiere los valores asociados a un espacio común histórico, que conduce en las postrimerías del dieciocho a un Estado con esencia nacional, utilizados ya conceptualmente en los despachos de la diplomacia francesa, y en sus embajadores residente en la Corte madrileña. La defensa de la legitimidad real conduce el proceso de la Guerra, pero el concepto de la monarquía ilustrada va perdiendo peso ante el descrédito del gobierno cortesano, la ruina económica y los nuevos ideales revolucionarios.

Paralelamente a esto, también existe una patria mallorquina y balear, asociada por vínculos consuetudinarios al propio lugar de nacimiento, al hogar de los ancestros. Esta contiene valores antropológicos y sociales, y de pertenencia cultural. Aparece en los hechos vinculados a la participación ciudadana, las jerarquías familiares, y los valores sociales. Es por ello, también, el histórico vinculo con Cataluña, que aunque se manifieste aquí en materias defensivas y de abastecimientos militares, recoge una tradición de ayuda material y de hombres, que se explica por una tradición de foralidad histórica sin rupturas aparentes desde los Austrias. Ambas patrias coexisten en la normalidad oficial y, sin lugar a dudas, en la mentalidad popular. Los mallorquinos salieron de sus casas para la defensa de sus dos patrias, en un manifiesto unánime de "afirmación frente al continente". 


\section{Apéndice}

\section{Cuadro I}

\begin{tabular}{|l|l|}
\hline Puertos de la isla & 10 \\
\hline Bahías & 4 \\
\hline Ensenadas & 12 \\
\hline Calas & 59 \\
\hline Castillos existentes & 8 \\
\hline Castillos proyectados & 1 \\
\hline Torres existentes artilladas & 24 \\
\hline Torres sin artillar & 3 \\
\hline Torres de vigía & 13 \\
\hline Torres proyectadas & 12 \\
\hline Baterías existentes artilladas & 9 \\
\hline Baterías sin artillar & 4 \\
\hline Baterías proyectadas & 6 \\
\hline Artillería existente & 89 \\
\hline Artillería proyectada & 52 \\
\hline
\end{tabular}

Fuente: AGS. Guerra Moderna, leg. 6447.

\section{Cuadro II}

\begin{tabular}{|l|c|c|}
\hline \multicolumn{3}{|l|}{ Guardias de las villas y pueblos } \\
\hline Nombre de los mismos & Quarteles & Hombres \\
\hline Andrache & 1 & 12 \\
\hline Caubia & 1 & 12 \\
\hline Soller & 1 & 12 \\
\hline Ynca & 1 & 70 \\
\hline Alcudia & 4 & 200 \\
\hline Pollensa & 1 & 400 \\
\hline Santa Margarita & 1 & 35 \\
\hline Artá & 1 & 70 \\
\hline Capdepera & 1 & 12 \\
\hline Manacor & 1 & 171 \\
\hline Felaniche & 1 & 35 \\
\hline Santañi & 1 & 12 \\
\hline Campós & 1 & 70 \\
\hline Llumaior & 1 & 70 \\
\hline Total General & $\mathbf{1 5}$ & $\mathbf{1 1}$ \\
\hline
\end{tabular}

Fuente: AGS. Guerra Moderna, leg. 6447. 


\section{Cuadro III}

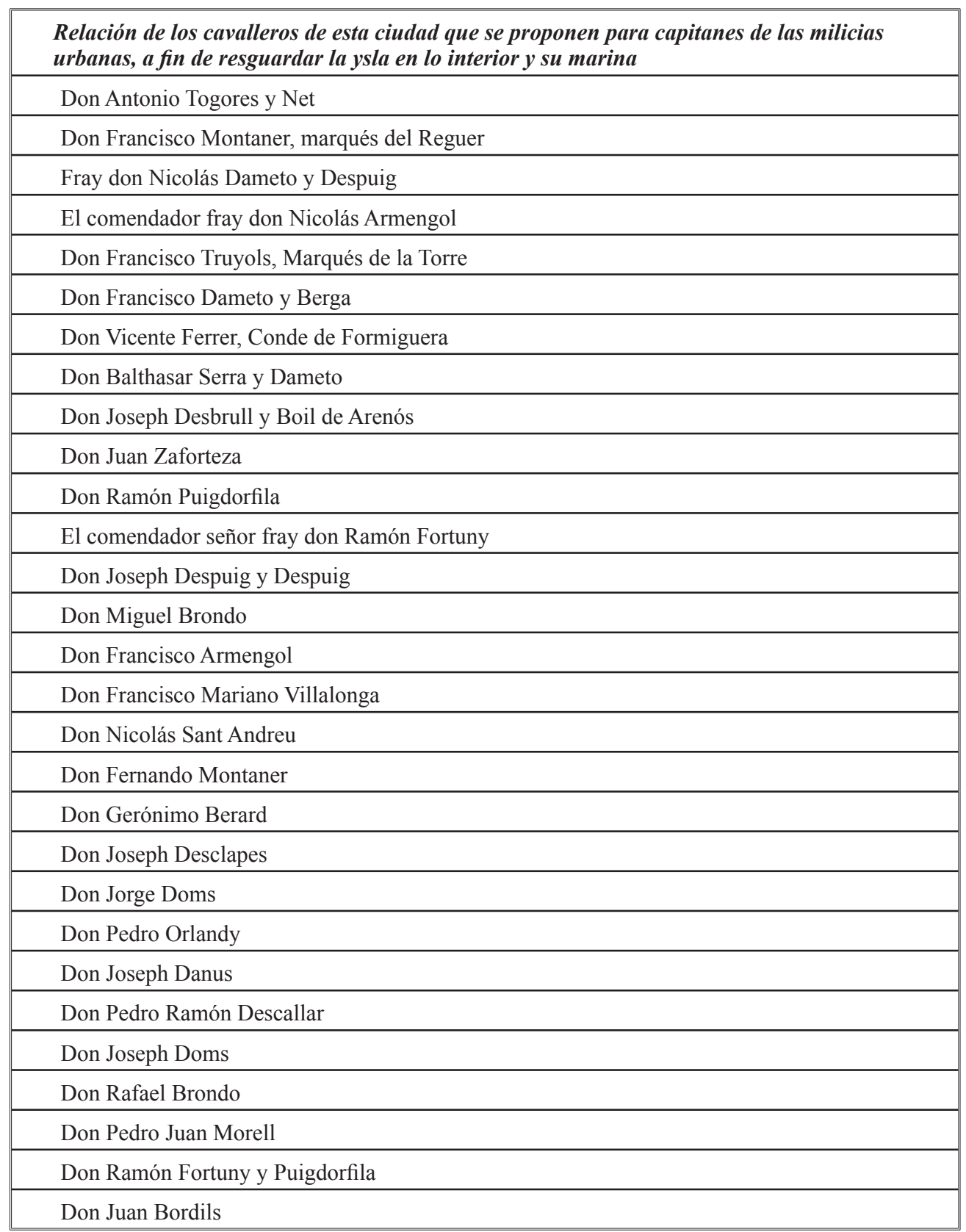

Fuente: AGS. Guerra Moderna, leg. 6447. 


\section{Cuadro IV}

\begin{tabular}{|c|c|c|c|c|c|}
\hline \multirow{3}{*}{ Nombre de las Villas } & \multicolumn{3}{|c|}{ Hombres } & \multirow{3}{*}{$\begin{array}{c}\text { Total de las } \\
\text { tres }\end{array}$} & \multirow{3}{*}{$\begin{array}{c}\text { Excepta- } \\
\text { dos }\end{array}$} \\
\hline & $1^{\circ}$ clase & $2^{\circ}$ clase & $3^{\circ}$ clase & & \\
\hline & 16-50 años & 50-60 años & 14-16 años & & \\
\hline Caubia & 262 & 53 & 7 & 322 & 45 \\
\hline Puig-Puñent & 222 & 28 & 6 & 256 & 20 \\
\hline Andrache & 412 & 114 & 30 & 556 & 38 \\
\hline Esporlas & 562 & 68 & 48 & 678 & 46 \\
\hline Estellenchs & 98 & 12 & 6 & 116 & 29 \\
\hline Banalbufar & 48 & 2 & 9 & 59 & 19 \\
\hline ValldeMosa & 229 & 20 & 15 & 264 & 38 \\
\hline Deya & 115 & 26 & 9 & 150 & 26 \\
\hline Soller & 936 & 154 & 67 & 1157 & 110 \\
\hline Buñola & 279 & 26 & 19 & 324 & 50 \\
\hline Marrachi & 219 & 33 & 11 & 266 & 27 \\
\hline Santa María & 585 & 110 & 42 & 737 & 35 \\
\hline Sensellas & 649 & 81 & 109 & 839 & 78 \\
\hline Alaro & 618 & 73 & 60 & 741 & 65 \\
\hline Binisalem & 424 & 29 & 38 & 491 & 42 \\
\hline Lioseta & 148 & 30 & 10 & 188 & 25 \\
\hline Ynca & 543 & 85 & 30 & 658 & 28 \\
\hline Escorca & 38 & 3 & 6 & 47 & 21 \\
\hline Selva & 566 & 66 & 47 & 679 & 65 \\
\hline Campanet & 552 & 73 & 33 & 658 & 34 \\
\hline Alcudia & 195 & 27 & 26 & 248 & 16 \\
\hline Pollensa & 856 & 145 & 68 & 1069 & 84 \\
\hline La Puebla & 454 & 23 & 32 & 509 & 36 \\
\hline Muro & 640 & 79 & 95 & 814 & 61 \\
\hline Santa Margarita & 463 & 41 & 40 & 544 & 80 \\
\hline Sineu & 694 & 39 & 54 & 787 & 48 \\
\hline San Juan & 295 & 29 & 21 & 345 & 34 \\
\hline Petra & 578 & 84 & 58 & 720 & 54 \\
\hline Manacor & 1505 & 113 & 143 & 1761 & 133 \\
\hline Arta & 1055 & 64 & 52 & 1171 & 59 \\
\hline Felaniche & 1216 & 229 & 142 & 1587 & 128 \\
\hline Santany & 590 & 80 & 61 & 731 & 62 \\
\hline Campos & 459 & 43 & 57 & 559 & 93 \\
\hline Porreras & 448 & 80 & 43 & 571 & 69 \\
\hline Montuiri & 353 & 42 & 22 & 417 & 46 \\
\hline Algaida & 531 & 30 & 87 & 648 & 53 \\
\hline Llumaior & 990 & 191 & 100 & 1287 & 144 \\
\hline Término de la ciudad & 584 & 107 & 28 & 719 & 12 \\
\hline Suma general & 1.9411 & 2.532 & 1.734 & 23.677 & 2.043 \\
\hline
\end{tabular}

Fuente: AGS. Guerra Moderna, leg. 6447. 